\title{
Osteoid osteomas and osteoblastomas of the spine
}

\author{
Mehmet Zileli, M.D., Sedat Çagli, M.D., GülÇın BaSdemir, M.D., \\ AND YUSUf ERSAhIN, M.D. \\ Departments of Neurosurgery and Pathology, Ege University Faculty of Medicine, Izmir, Turkey
}

\begin{abstract}
Object. Osteoid osteomas and osteoblastomas are rare primary bone tumors that usually do not arise in the spine. In this report the authors analyze 16 cases of osteoid osteoma or osteoblastoma of the spine that were surgically treated over a 27-year period.

Methods. A retrospective study was conducted in which the following data were found: five patients had osteoid osteomas (two male and three female patients) and 11 had osteoblastomas (seven male and four female patients). The site of the tumor was the cervical spine in four, thoracic in six, and lumbar spine in six. In 14 patients, the tumor involved the posterior vertebral elements, with lumbar and thoracic levels being the most common. Only two patients had tumors in the body of a cervical vertebra. The mean age of the patients was 20 years for osteoid osteoma and 19 years for osteoblastoma. The most common symptom was local pain in the area of the tumor. Among 11 patients with osteoblastoma, six (two with paraparesis, four with monoparesis) had neurological deficits caused by extradural compression. None of the patients with osteoid osteoma had neurological deficits. The diameters of osteoblastomas were 3 to $8 \mathrm{~cm}$ (mean $4 \mathrm{~cm}$ ), and those of osteoid osteomas were 1.5 to $2 \mathrm{~cm}$ (mean $1.7 \mathrm{~cm}$ ). Although the peritumoral bone was normal in patients with osteoblastoma, a sclerotic rim was observed in all patients with osteoid osteoma.

All patients were treated with resection; tumor excision was complete in 15 cases. Follow-up periods ranged from 2 months to 13 years (mean 36 months). Complete pain relief was achieved in 15 patients; the other patient described mild pain with activity. There was no tumor recurrence except one regrowth in a patient with osteoblastoma who then received radiation therapy. There were two complications: one surgery was performed at the wrong level, and there was one instrument failure that required revision.

Conclusions. With the help of modern imaging modalities that aid in diagnosis and surgical planning, a complete removal and cure may be achieved for most of these rare tumors.
\end{abstract}

\section{KEY WORDS • bone tumor • spine tumor • osteoid osteoma $\bullet$ osteoblastoma $\bullet$ spine surgery}

In $1935 \mathrm{Jaffe}^{13}$ described a new bone lesion, which he named osteoid osteoma. This entity arose in spongy bone and was less than $2 \mathrm{~cm}$ in diameter; Jaffe was the first to identify and describe osteoid osteoma of the spine. In 1956, Jaffe ${ }^{14}$ and Lichtenstein ${ }^{18}$ independently proposed the term "benign osteoblastoma." Osteoid osteomas and osteoblastomas are bone-producing lesions that are frequently localized in long bones and posterior elements of the vertebra. The most common presenting symptom is pain. Histologically, osteoid osteomas and osteoblastomas are similar. Findings on plain x-ray films and CT studies are similar in both tumor types, and include radiolucent nidus, matrix calcifications, and accompanying osseous sclerosis. Their most remarkable difference is that osteoblastoma has an unlimited growth potential with a capability of malignant transformation, and it is larger (usually $>2 \mathrm{~cm}$ ). The usual site for both tumor types is the neural arch.

The purpose of this retrospective study is to analyze the natural history, presentation, treatment, results, and complications in osteoid osteomas and osteoblastomas of the spine.

Abbreviations used in this paper: $\mathrm{CT}=$ computerized tomography; $\mathrm{MR}=$ magnetic resonance; $\mathrm{VB}=$ vertebral body.

\section{CLINICAL MATERIAL AND METHODS}

\section{Patient Population}

Sixteen patients with pathologically confirmed diagnoses of osteoid osteoma or osteoblastoma of the spine were surgically treated in our department over a 27 -year period (1976-2003). On histopathological examination, any lesion with a diameter smaller than $2 \mathrm{~cm}$ was arbitrarily considered to be an osteoid osteoma, and one larger than $2 \mathrm{~cm}$ was diagnosed as an osteoblastoma. The original pathological reports confirming the diagnosis of osteoid osteoma and osteoblastoma were available in all cases. The neuroimaging findings assessed included the size and location of the lesion and the configuration and degree of sclerosis of its peripheral margin. By these criteria, five patients had an osteoid osteoma (two male and three female patients) and 11 (seven male and four female patients) had an osteoblastoma. There were nine male patients (two with osteoid osteoma and seven with osteoblastoma) and seven female patients (three with osteoid osteoma and four with osteoblastoma), showing a strong preponderance of osteoblastomas in male patients (Table 1).

The site of the tumor was the cervical (four patients), thoracic (six patients), and lumbar spine (six patients). In 14 patients, the tumor involved the posterior vertebral ele- 
TABLE 1

Summary of findings in 16 patients treated for osteoblastoma or osteoid osteoma of the spine*

\begin{tabular}{|c|c|c|c|c|c|c|c|c|}
\hline $\begin{array}{l}\text { Case } \\
\text { No. }\end{array}$ & $\begin{array}{l}\text { Age (yrs), } \\
\text { Sex }\end{array}$ & $\begin{array}{l}\text { Histological } \\
\text { Diagnosis }\end{array}$ & $\begin{array}{l}\text { Symptoms \& } \\
\text { Duration (mos) }\end{array}$ & $\begin{array}{l}\text { Physical \& Neuro- } \\
\text { logical Findings }\end{array}$ & $\begin{array}{l}\text { Localization } \\
\quad \text { (level) }\end{array}$ & $\begin{array}{l}\text { Max Diam- } \\
\text { eter }(\mathrm{cm})\end{array}$ & Type of Op & $\begin{array}{l}\mathrm{FU} \\
(\mathrm{mos})\end{array}$ \\
\hline 1 & $41, \mathrm{M}$ & osteoblastoma & leg weakness (10) & $\begin{array}{r}\text { paraparesis, cauda } \\
\text { equina syndrome }\end{array}$ & lamina $(\mathrm{T}-10)$ & 5 & laminectomy & 120 \\
\hline 2 & $10, \mathrm{~F}$ & osteoblastoma & leg weakness (3) & monoparesis & lamina (T-6) & 4 & laminectomy, facetectomy & 34 \\
\hline 3 & $8, \mathrm{~F}$ & osteoblastoma & leg weakness (7) & monoparesis & pedicle (L-2) & 3 & $\begin{array}{l}\text { laminectomy, facetectomy, } \\
\text { pedicle excision }\end{array}$ & 46 \\
\hline 4 & $14, \mathrm{M}$ & osteoblastoma & leg weakness (1) & paraparesis & $\begin{array}{l}\text { transverse pro- } \\
\text { cess }(\mathrm{T}-5)\end{array}$ & 4 & $\begin{array}{l}\text { laminectomy, facetectomy, } \\
\text { pedicle \& transverse } \\
\text { process excision }\end{array}$ & 24 \\
\hline 5 & $21, \mathrm{~F}$ & osteoblastoma & neck \& lt arm pain (60) & normal & VB (C5-6) & 3 & $\begin{array}{l}\text { cervical anterolat approach, } \\
\text { corpectomy, bone graft }\end{array}$ & 36 \\
\hline 6 & $6, \mathrm{M}$ & osteoblastoma & low-back \& lt leg pain (24) & scoliosis & $\begin{array}{l}\text { lamina, facet } \\
\text { joint }(\mathrm{L}-4)\end{array}$ & 6 & laminectomy & 60 \\
\hline 7 & $22, \mathrm{M}$ & osteoblastoma & neck pain (6) & normal & $\begin{array}{l}\text { lamina, facet } \\
\text { joint (T1-2) }\end{array}$ & 5 & laminectomy, facetectomy & 50 \\
\hline 8 & $10, \mathrm{M}$ & osteoblastoma & neck pain \& swelling (24) & dysarthria & VB $(C-2)$ & 5 & $\begin{array}{l}\text { retropharyngeal anterolat } \\
\text { approach, occipitocervical } \\
\text { fixation }\end{array}$ & 45 \\
\hline 9 & $41, \mathrm{~F}$ & osteoblastoma & leg weakness (5) & monoparesis & lamina (L-2) & 4 & $\begin{array}{l}\text { laminectomy, facetectomy, } \\
\text { pedicle excision }\end{array}$ & 48 \\
\hline 10 & $7, \mathrm{M}$ & osteoblastoma & leg weakness (2) & monoparesis & lamina (L-3) & 1 & laminectomy & 10 \\
\hline 11 & $29, \mathrm{M}$ & osteoblastoma & low-back pain (24) & normal & lamina (L3-4) & 2 & laminectomy & 1 \\
\hline 12 & $17, \mathrm{~F}$ & osteoid osteoma & neck pain (12) & normal & lamina (C2-3) & 2 & laminectomy & 36 \\
\hline 13 & $20, \mathrm{~F}$ & osteoid osteoma & lt thoracic pain (12) & normal & $\begin{array}{l}\text { lamina, facet } \\
\text { joint (T4-5) }\end{array}$ & 2 & laminectomy & 60 \\
\hline 14 & $16, \mathrm{M}$ & osteoid osteoma & neck pain (2) & normal & pedicle $(\mathrm{C}-5)$ & 1.5 & laminectomy & 12 \\
\hline 15 & $23, \mathrm{M}$ & osteoid osteoma & low-back \& lt leg pain (24) & normal & facet joint (L-4) & 2 & laminectomy & 2 \\
\hline 16 & $24, \mathrm{~F}$ & osteoid osteoma & thoracic pain $(36)$ & normal & pedicle (T-10) & 1.5 & laminectomy & 2 \\
\hline
\end{tabular}

* None of the osteoblastomas had a sclerotic rim, whereas all of the osteoid osteomas did. Complications arose in Case 4 (instrument failure necessitating revision) and in Case 13 (wrong level resected, necessitating reoperation). Abbreviation: FU = follow up.

ments, with lumbar and thoracic levels the most common. Only two patients had tumor in the body of a cervical vertebra. The location of each type of tumor within the spine and within the VBs is given in Table 2.

The mean age of the patients at the onset of symptoms was 20 years for osteoid osteoma and 19 years for osteoblastoma. The duration of symptoms prior to diagnosis was 1 to 60 months (mean 15.7 months). Symptom duration in patients with osteoid osteoma was $22 \pm 14.9$ months, and in patients with osteoblastoma it was $18.4 \pm$ 16.1 months (mean \pm standard deviation). The most common symptom was local pain in the area of the tumor. All patients reported continuous local pain, with only the five with osteoid osteoma noting an increase in pain at night. Eight patients reported increasing pain, with longer duration of symptoms. The descriptions of pain ranged from a dull throb to episodic sharp, stabbing pain to knifelike

TABLE 2

Distribution of lesions in patients with osteoid osteoma and osteoblastoma of the spine

\begin{tabular}{lccc}
\hline \hline Location & $\begin{array}{c}\text { Total No. } \\
\text { of Patients }\end{array}$ & $\begin{array}{c}\text { Osteoid } \\
\text { Osteoma }\end{array}$ & Osteoblastoma \\
\hline cervical & 4 & 2 & 2 \\
thoracic & 6 & 2 & 4 \\
lumbar & 6 & 1 & 5 \\
total & 16 & 5 & 11 \\
\hline
\end{tabular}

pain. Paravertebral muscle spasm and marked spinal stiffness were observed in 12 patients. Only one patient, who had an osteoblastoma in L-4 had scoliosis. Among the 11 patients with osteoblastoma, six experienced neurological deficits caused by extradural compression (two with paraparesis and four with monoparesis). None of the patients with osteoid osteoma had neurological deficits.

\section{Neuroimaging Findings}

All patients underwent X-ray and CT studies; MR imaging was performed in six patients. Diagnosis based on neuroimaging findings was often difficult initially when lesions were small. The plain $\mathrm{x}$-ray films aided diagnosis when lesions were located in the spinous process or transverse process. For lesions primarily involving the lamina, pedicle, or VB, the diagnosis could be made with the aid of CT and MR studies. The diameters of osteoblastomas were 3 to $8 \mathrm{~cm}$ (mean $4 \mathrm{~cm}$ ), and osteoid osteomas were 1.5 to $2 \mathrm{~cm}$ (mean $1.7 \mathrm{~cm}$ ) in diameter. Although the peritumoral bone was normal in patients with osteoblastoma, a sclerotic rim was observed in osteoid osteomas.

\section{Surgical Procedures}

All patients underwent tumor resection. Fourteen patients were treated via a posterior approach with removal of the abnormal laminae, pedicle, transverse process, and facet joint. One patient with an osteoblastoma underwent a laminectomy and stabilization with posterior instrumentation. In another patient with an osteoblastoma invading 
the $\mathrm{C}-2 \mathrm{VB}$, the tumor was resected via a retropharyngeal anterolateral approach and the patient underwent a posterior occipitocervical stabilization and bone grafting. One patient with a C-5 VB osteoblastoma underwent corpectomy and bone fusion. Tumor excision was complete in 15 patients. Postoperative radiation therapy was delivered to the thoracic spine of a patient with T-10 osteoblastoma after incomplete removal of the tumor. None of the other patients received adjuvant therapy after surgery.

\section{Histological Findings}

On histological examination osteoid osteoma consists of a small $(<1.5-2 \mathrm{~cm})$, yellowish to red nidus of osteoid and woven bone with interconnected trabeculae, and a background and rim of highly vascularized, fibrous connective tissue. Varying degrees of sclerotic bone reaction may surround the lesion. Benign osteoblastoma is virtually indistinguishable from osteoid osteoma. The usual appearance included a fibrovascular stroma with numerous osteoblasts, osteoid tissue, well-formed woven bone, and giant cells. The osteoblasts were generally small and regular in shape. A typical case of osteoblastoma and its histological features is depicted in Figs. 1 and 2, and a case of osteoid osteoma and its histological features is depicted in Figs. 3 and 4.

\section{Postoperative Outcome}

The results of surgery have been satisfactory in all cases, with follow-up periods ranging from 2 months to 13 years (mean 3 years). Complete pain relief was achieved in 15 patients; the remaining patient described mild pain with activity. There has been no tumor recurrence except in one patient with osteoblastoma.

There were two complications: in one patient with a T-6 osteoid osteoma, the initial surgical procedure was performed at the wrong level and a second operation was required to remove osteoid osteoma from the facet joint. In the other patient, a 14-year-old boy with T-5 osteoblastoma, a revision surgery was necessary because of instrument failure. This patient had undergone posterior fixation with a hook and rod system after tumor removal. Two years postsurgery the upper hooks on one side had loosened and the rod was dislocated, necessitating removal of the instrument. Repeated MR imaging demonstrated no recurrence of osteoblastoma.

\section{DISCUSSION}

After the first descriptions of osteoid osteoma and osteoblastoma by Jaffe ${ }^{13,14}$ and Lichtenstein, ${ }^{18}$ these rather vascular, osteoid, and bone-forming tumors caught the attention of different authors. Jackson, et al., ${ }^{12}$ published a review of 860 cases of osteoid osteoma and 184 cases of osteoblastoma collected from the English literature. The spine has been the location of $10 \%$ of all osteoid osteomas $^{2,7,12,28}$ and $36 \%$ of osteoblastomas. These spine tumors arose mainly from posterior elements. The osteoid osteomas in our series occurred predominantly in the posterior elements, especially the lamina and pedicles. When neuroimaging permitted delineation, the majority of the tumors arose in the lamina and pedicles, and most of the others were found in the transverse and spinous processes.
When present, VB involvement was very limited and was secondary to anterior extension of the tumor. Both of these tumor types tend to occur in the thoracic and lumbar spine, ${ }^{5,26}$ as demonstrated in this series. They also involve the posterior arch much more frequently than the VB. In addition, osteoblastomas of the spine may have soft-tissue masses, which initially may encroach on the spinal canal and later may surround the dural sac or adjacent nerve roots, or both. Osteoblastomas occur predominantly in patients younger than 20 years of age. ${ }^{8,14,18}$ The youngest reported patient was 2 years old and the oldest was 78 years old. ${ }^{11,23}$

Clinically, the pain of osteoblastoma is not as severe at night, nor is it relieved by aspirin, as was the pain of osteoid osteoma. When these lesions occur in the spine, two important manifestations are frequently evident: scoliosis and neurological involvement. The occurrence of scoliosis has been reported frequently, 1,5,6,20,21,26 although we treated only one patient with this condition. The incidence of neurological deficits is significantly higher in patients with osteoblastoma than in those with osteoid osteoma. ${ }^{5,15,20,21}$ In our series, the incidence of significant neurological deficits is much higher in osteoblastomas (six of 11) than in osteoid osteomas. (In fact, none of the patients with osteoid osteoma in our series had neurological deficits.) Recovery from these deficits was complete. The presenting symptom of spinal osteoblastoma is a neurological deficit in approximately 25 to $50 \%$ of cases. ${ }^{6,26}$

In contrast to osteoid osteomas, plain $\mathrm{x}$-ray films are usually sufficient to diagnose osteoblastomas, although CT scans and MR images are of great value for both diagnostic and therapeutic considerations in the spine. Preoperative CT scanning has been shown to be very helpful for precisely defining the location of the tumor and the extent of osseous involvement. ${ }^{10}$ The appearance of these tumors on MR images is generally nonspecific, but this imaging modality is surely the best to reveal the effects of tumor on the spinal canal and cord, as well as the extensive intra- and extraosseous reactive changes and the possible infiltration of adjacent soft tissues. The nidus usually has a low to intermediate signal intensity on $\mathrm{T}_{1}$ weighted and a low-to-high signal intensity on $\mathrm{T}_{2}$-weighted MR images. ${ }^{3,9,24}$ Technetium bone scanning is now accepted as the most accurate means for localizing the tumor. ${ }^{26}$ This modality demonstrates an intense focal accumulation of the bone-seeking agent. ${ }^{17,25}$ If the lesion is already discernible on x-ray films, the scintigram is unnecessary, as we have found in this series. We recommend considering routine preoperative testing with CT scanning and MR imaging for every patient.

As a result of their histological similarity, osteoid osteomas and osteoblastomas are frequently considered together when assessing methods of evaluation and treatment. This is especially true in the spine, ${ }^{15,16,26,27}$ where the overall incidence of these lesions is quite low. On histological examination, the lesions are similar, ${ }^{8,12}$ consisting of a discrete osteoid nidus that varies in consistency from soft and granular to densely sclerotic. When located in cancellous bone, a dense, sclerotic rim surrounds the tumor. The primary difference between the two lesions is the tendency of osteoblastoma to form a less sclerotic but more expansile mass. ${ }^{8,12,15}$

Osteoid osteoma is the lesion most closely related to os- 
M. Zileli, et al.

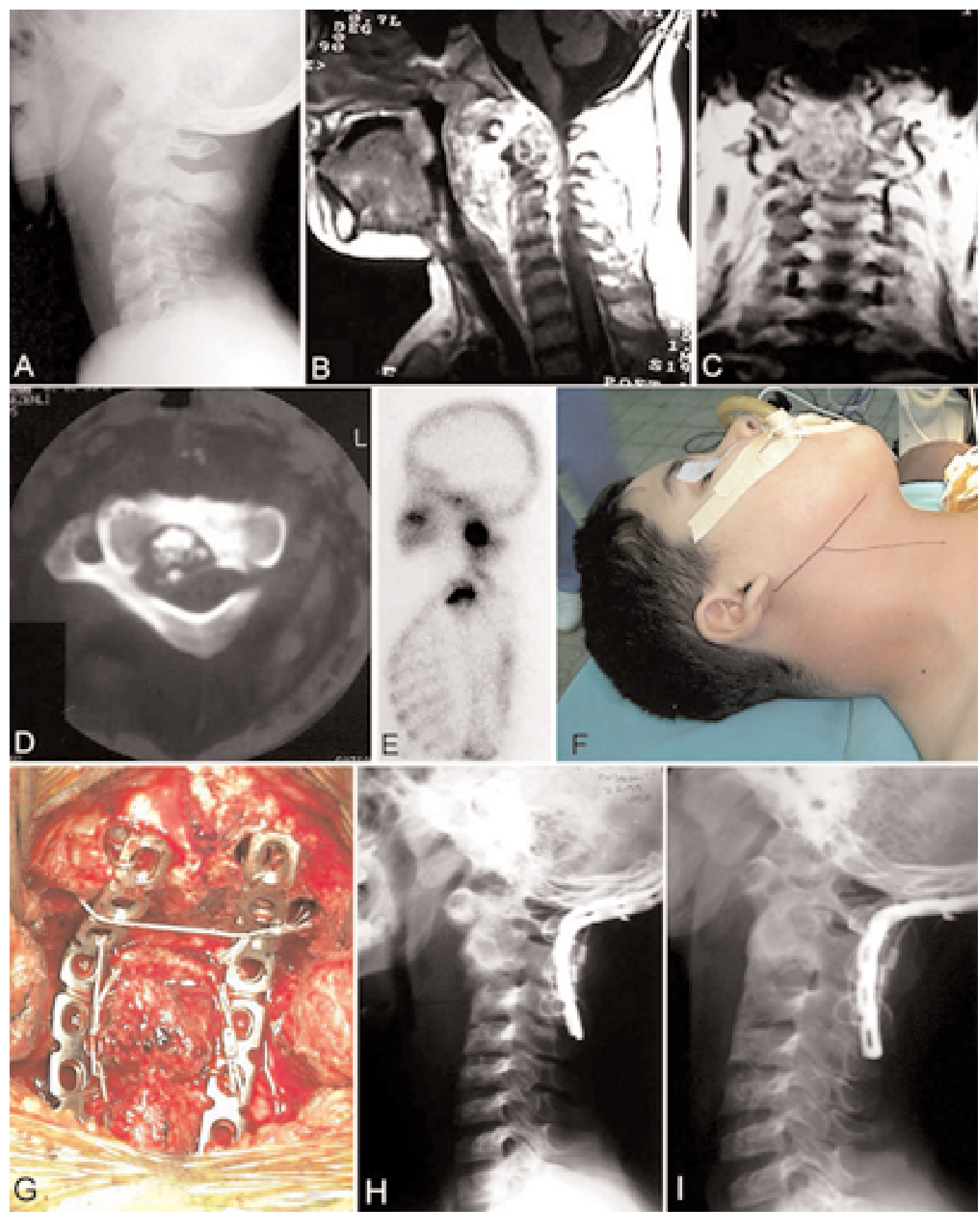

Fig. 1. Case 8. Diagnostic images of C-2 osteoblastoma. This 10-year-old boy presented with neck pain, and on physical examination local swelling was found on right cervical region. Lateral x-ray films (a) showed a soft-tissue swelling in the retropharyngeal space. Lateral (b) and coronal (c) MR images demonstrating tumor in the C-2 body and a soft-tissue mass from C1-6. Axial CT scan (d) demonstrating a typical osteoid nidus with peritumoral sclerotic rim on the right side of the C-2 body. Technetium bone scan (e) also displays pronounced uptake in this region. We performed tumoe excision via an anterolateral retropharyngeal approach (f) occipitocervical fixation by using two axis plates and titanium wires (g). Lateral x-ray films obtained immediately after (h) and 2 years postsurgery (i) showing solid fusion.

teoblastoma histologically, although the nidus characteristic of osteoid osteoma is not found in osteoblastoma. Also, the large vascular spaces and reactive giant cells commonly seen in osteoblastoma are rare in osteoid osteoma. ${ }^{21}$

None of the patients in our series had lesions in an "aggressive" subcategory, nor did they have malignant osteo- blastoma. ${ }^{29-31}$ Such lesions have a very destructive appearance on neuroimaging, and are more cellular than the benign type described in this series, with swollen, plump osteoblasts observed on histological examination. Because of a high recurrence rate, the need for wide excision of these malignant tumors is clear. 


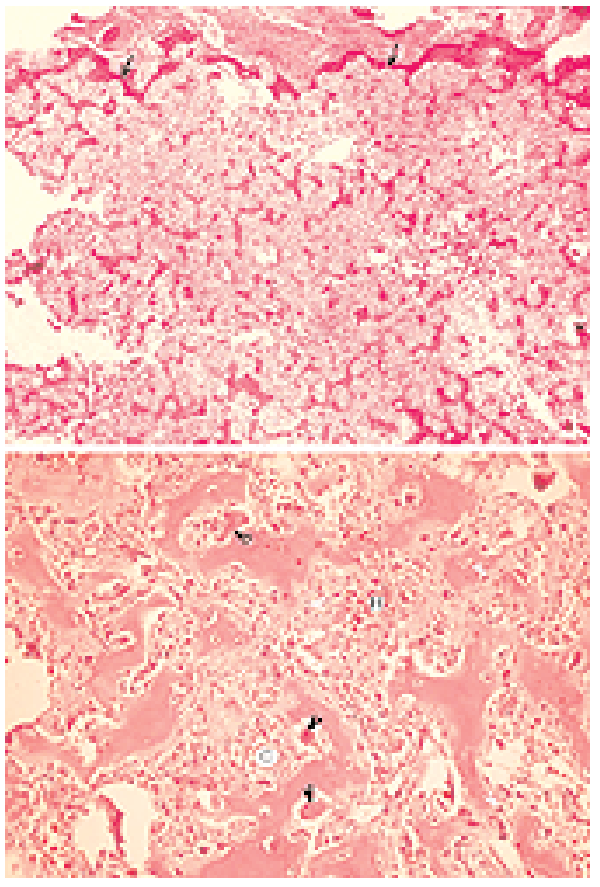

Fig. 2. Case 8. Histological studies of osteoblastoma. Upper: Photomicrograph showing packed, small, irregular trabeculae composed of pure woven bone and osteoid. A shell of ossification (arrows), (expanded and thinned cortex) is seen at the periphery of the osteoblastoma. Intertrabecular stroma is abundant and cellular. Lower: Photomicrograph showing that intense proliferation of cells occurs between irregularly serrated, thick woven bone trabeculae. The cells consist of osteoblasts (small arrows), osteoclasts (large arrows), and spindly stromal cells. This field also shows numerous dilated capillaries $(\mathrm{C})$ and foci of hemorrhage $(\mathrm{H})$. $\mathrm{H} \& \mathrm{E}$, original magnifications $\times 40$ (upper) and $\times 200$ (lower).

Surgery is the most common treatment for this disease, and the prognosis after total resection is favorable. The recommended treatment for osteoid osteoma causing disabling pain and spinal deformity is excision. The most im-

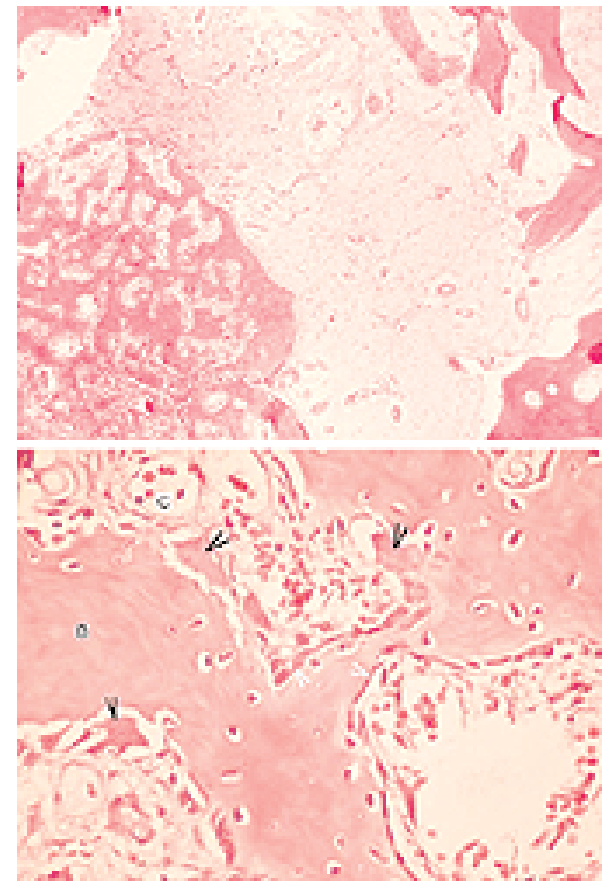

Fig. 4. Case 14. Histological studies of osteoid osteoma. Upper: Photomicrograph in which the nidus reveals contiguously joined trabeculae of well-calcified, woven bone at the left side. The thick bone trabeculae at right consist of host lamellar woven bone. The interface between the lesion and the surrounding host bone trabeculae is demarcated by a sheet of loose fibrovascular tissue. Lower: Photomicrograph showing a prominent single row of osteoblastic rim (white arrows), curved trabeculae of primitive woven bone (B), and a few osteoclasts (black arrows). The loose fibrovascular stroma is generally rich in thin-walled, dilated capillaries $(C)$. $\mathrm{H} \& \mathrm{E}$, original magnifications $\times 40$ (upper) and $\times 400$ (lower).

portant determinant for successful removal of the tumor is its exact localization. Osteoid osteomas are most frequently treated because of the persistent pain associated with them, whereas osteoblastomas are treated both for
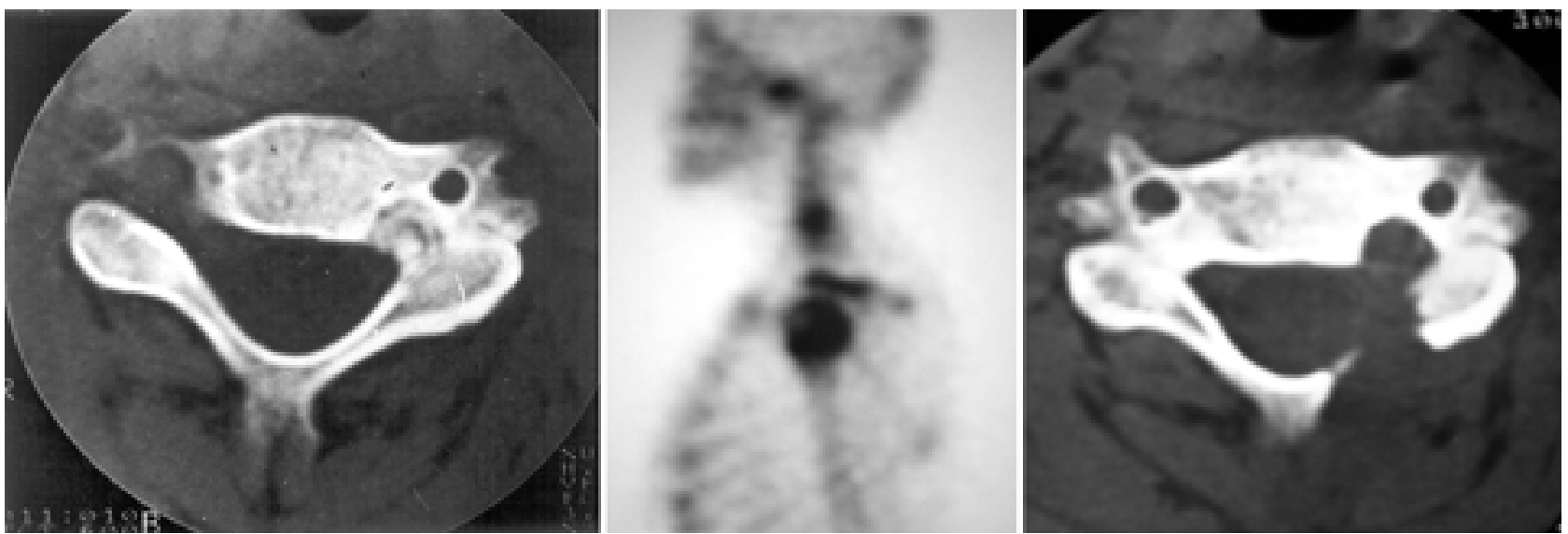

Fig. 3. Case 14. Diagnostic images of C-5 osteoid osteoma. This 16-year-old man presented with neck pain only. Axial CT scan (left) revealing that a tumor arising from the left C-5 pedicle is compressing the left C-5 root. A technetium bone scan (center) displays high uptake of contrast material. Axial CT scan (right) demonstrating that left hemilaminectomy was sufficient to remove the tumor. 
pain and the increase in size, which leads to destruction of bone.

In this series tumor excision was intralesional in most cases. Most osteoblastomas were multilobular, with extension into the paraspinal areas, and their locations in cervical or lower lumbar regions (two cases each) did not allow en bloc resections. Therefore, extramarginal excisions could be performed in only three patients with osteoblastomas.

Osteoblastomas recur in approximately 9.8 to $15 \%$ of cases; $4,6,19,22$ recurrence is the result of incomplete resection. These lesions hardly ever undergo a malignant transformation into osteosarcoma and metastasize.,22 Most importantly, however, the recurrence/persistence rate is statistically lower in osteoid osteomas $(4.5 \%),{ }^{12}$ which have no potential for malignant transformation.

Differentiation between these tumors and fibrous dysplasia, osteosarcoma, giant cell bone tumor, or aneurysmal bone cyst is necessary. It is relatively easy to distinguish osteoblastoma from these tumors histologically, and to exclude osteoid osteoma.

\section{CONCLUSIONS}

Primary osseous tumors of the spine are rare lesions that are much less frequently encountered than metastases, multiple myeloma, and lymphoma. The goal of surgery should be complete removal whenever possible. When tumor excision results in instability of the vertebral column, concurrent spinal stabilization and fusion should be performed. Instability may occur in large lesions involving the facet joints or pedicle, and with tumors invading the upper cervical spine. With the development of modern imaging methods, exact surgical planning has become possible.

\section{References}

1. Akbarnia BA, Rooholamini SA: Scoliosis caused by benign osteoblastoma of the thoracic or lumbar spine. J Bone Joint Surg Am 63:1146-1155, 1981

2. Azouz EM, Kozlowski K, Marton D, et al: Osteoid osteoma and osteoblastoma of the spine in children. Report of 22 cases with brief literature review. Pediatr Radiol 16:25-31, 1986

3. Bartolozzi P, Floris G: Osteoid osteoma of the body of the first sacral vertebra. Case report. Ital J Orthop Traumatol 14: 527-528, 1988

4. Bloem JL, Kroon HM: Osseous lesions. Radiol Clin North Am 31:261-278, 1993

5. Boriani S, Capanna R, Donati D, et al: Osteoblastoma of the spine. Clin Orthop 278:37-45, 1992

6. Cerase A, Priolo F: Skeletal benign bone-forming lesions. Europ J Radiol 27 (Suppl 1):S91-S97, 1998

7. Cové JA, Taminiau AH, Obermann WR, et al: Osteoid osteoma of the spine treated with percutaneous computed tomographyguided thermocoagulation. Spine 25:1283-1286, 2000

8. Dahlin, DC: Bone Tumors: General Aspects and Data on 6, 221 Cases. Springfield, IL: Charles C Thomas, 1978

9. De Boeck H, Casteleyn PP, Bossuyt A, et al: Intraoperative radioactive localization of small bone tumours. Int Orthop 16:
$172-175,1992$

10. Herrlin K, Ekelund L, Lövdahl R, et al: Computed tomography in suspected osteoid osteomas of tubular bones. Skeletal Radiol 9:92-97, 1982

11. Huvos AG: Bone Tumors: Diagnosis, Treatment and Prognosis, ed 2. Philadelphia: WB Saunders, 1991

12. Jackson RP, Reckling FW, Mants FA: Osteoid osteoma and osteoblastoma. Similar histologic lesions with different natural histories. Clin Orthop 128:303-313, 1977

13. Jaffe HL: Benign osteoblastoma. Bull Hosp Joint Dis 17: $141-151,1956$

14. Jaffe HL: "Osteoid-osteoma": a benign osteoblastic tumor composed of osteoid and atypical bone. Arch Surg 31:709-728, 1935

15. Janin Y, Epstein JA, Carras R, et al: Osteoid osteomas and osteoblastomas of the spine. Neurosurgery 8:31-38, 1981

16. Kirwan EO, Hutton PA, Pozo JL, et al: Osteoid osteoma and benign osteoblastoma of the spine. Clinical presentation and treatment. J Bone Joint Surg Br 66:21-26, 1984

17. Kroon HM, Schurmans J: Osteoblastoma: clinical and radiological findings in 98 new cases. Radiology 175:783-790, 1990

18. Lichtenstein L: Benign osteoblastoma: A category of osteoidand bone forming tumors other than classical osteoid osteoma, which may be mistaken for giant-cell tumor or osteogenic sarcoma. Cancer 9:1044-1052, 1956

19. Lucas DR, Unni KK, McLeod RA, et al: Osteoblastoma: clinicopathologic study of 306 cases. Hum Pathol 25:117-134, 1994

20. MacLellan DI, Wilson FC Jr: Osteoid osteoma of the spine. A review of the literature and report of six new cases. J Bone Joint Surg Am 49:111-121, 1967

21. Marsh BW, Bonfiglio M, Brady LP, et al: Benign osteoblastoma: range of manifestations. J Bone Joint Surg Am 57:1-9, 1975

22. Mitchell ML, Ackerman LV: Metastatic and pseudomalignant osteoblastoma: a report of two unusual cases. Skeletal Radiol 15:213-8, 1986

23. Myles ST, MacRae ME: Benign osteoblastoma of the spine in childhood. J Neurosurg 68:884-888, 1988

24. Nasr FW, Sarru EA, Haddad FS: Sacral osteoid osteoma in a 10 year old girl. J Med Liban 40:216-218, 1992

25. Nemoto O, Moser RP Jr, Van Dam BE, et al: Osteoblastoma of the spine. A review of 75 cases. Spine 15:1272-1280, 1990

26. Pettine KA, Klassen RA: Osteoid-osteoma and osteoblastoma of the spine. J Bone Joint Surg Am 68:354-361, 1986

27. Ransford AO, Pozo JL, Hutton PA, et al: The behaviour of the scoliosis associated with osteoid osteoma or osteoblastoma of the spine. J Bone Joint Surg Br 66:16-20, 1984

28. Raskas DS, Graziano GP, Herzenberg JE, et al: Osteoid osteoma and osteoblastoma of the spine. J Spinal Disord 5: 204-211, 1992

29. Revell PA, Scholtz CL: Aggressive osteoblastoma. J Pathol 127:195-198, 1979

30. Seki T, Fukada H, Ishii Y, et al: Malignant transformation of benign osteoblastoma. A case report. J Bone Joint Surg Am 57: 424-426, 1975

31. Tonai M, Campbell CJ, Ahn GH, et al: Osteoblastoma: classification and report of 16 patients. Clin Orthop 167:222-235, 1982

Manuscript received September 17, 2003.

Accepted in final form October 10, 2003.

Address reprint requests to: Mehmet Zileli, M.D., Department of Neurosurgery, Ege University Faculty of Medicine, Bornova, Izmir 35100 Turkey. email: zileli@ttnet.net.tr. 
Title

Neurosurg. Focus / Volume 15 / November, 2003 